\title{
Plus ça change - The failure of PIAAC to drive evidence-based policy in Canada
}

\author{
Ralf St. Clair
}

Received: 15 May 2016 / Accepted: 29 July 2016/ Published online: 21 August 2016

(C) The Author(s) 2016. This article is available at SpringerLink with Open Access.

\begin{abstract}
The author discusses the influence of the Program for the International Assessment of Adult Competencies (PIAAC) on the literacy education field in Canada. Methodology is holistic and centred around critical policy analysis. Finds Canada invested heavily in the surveys and has not yet changed policy or practice in response to the findings. Two reasons for lack of influence are suggested: the difficulty of comparing literacy survey results over time, and the lack of federal investment in the organisations capable of putting the results into practice. Concludes with suggestions for bringing PIAAC and practice closer together.
\end{abstract}

Keywords PIAAC $\cdot$ Adult literacy $\cdot$ Canada $\cdot$ Policy analysis

Over the last twenty years, the availability of data regarding the population's basic skill levels and the factors likely to influence these levels increased steadily. This has transformed the discourse around basic skills. Whether policymakers have chosen to adopt and apply the measures or not, the existence of the data has created a new context for adult literacy education. There is little evidence that the potential to compare jurisdictions has been fulfilled, perhaps because it is difficult to know what such comparisons signify on a concrete level. However, there are many examples of national responses to the data and some significant efforts to work with the insights the Program for the International Assessment of Adult Competencies (PIAAC) provides.

In this discussion, I look at a range of applications and uses of the PIAAC information in one of the countries that contributed most to the development of the international literacy surveys. Due to the long history with the surveys in

R. St. Clair $(\bowtie)$

University of Victoria, Victoria, Canada

E-Mail: rstclair@uvic.ca 
Canada - and perhaps also due to the considerable sums invested - there have been a number of attempts to move from PIAAC data as "interesting information" to using the data to inform programming and policy directly. PIAAC is the third in a series of international adult literacy surveys, which in Canada began with the 1994 International Adult Literacy Survey (IALS), continued with the 2003 Adult Literacy and Lifeskills Survey (ALLS), and most recently the 2012 PIAAC.

In this discussion, I begin with methodology before moving into the context for literacy education and the history of PIAAC in Canada. I turn then to policy and practice in Canada, arguing that the impact of the PIAAC, and indeed the whole series of surveys, has been limited. I will close by suggesting possible ways ahead for the international literacy surveys in Canada and more broadly. While I have some concerns about the methodology and philosophy of the survey series (St. Clair 2013) I do believe there are opportunities to find value within it.

\section{Background}

The current paper is intended to provide a summative, holistic view of policy developments in Canada based on my experience and knowledge of the field. I have been involved in Canadian adult literacy education for over twenty years, and has conducted a number of studies on, and in, the field. I have also been involved in managing fieldwork for a national survey so I am aware of many of the procedures principles underlying the data collection and analysis. The key question I address here is the extent to which it is possible to discern effects of the PIAAC study on the adult literacy field. This matters a great deal - Canada led the way in the development of the survey and invested very heavily in it, as discussed below. Yet, there is little evidence that the survey changed very much, and that is what I am setting out to understand and address.

PIAAC is the latest in a series of international surveys, including IALS and ALLS. Each of these surveys looks at literacy (sometimes broken into sub-components of prose and document) and numeracy (really quantitative literacy-working with numbers in a text). The latest two versions also look at additional areas, either life skills or problem-solving using technology. The surveys are conducted in respondents' homes, making them extremely expensive to conduct.

The number of countries involved in the survey has changed each time, and very often additional countries join in after the first round of data collection is complete. It can be challenging to find out the final number of countries involved in a specific survey, but for the PIAAC the tally is approaching 40 countries and over 200,000 respondents (OECD 2016). This is an extremely large-scale endeavour.

The actual instruments involve respondents writing in answers to a series of questions. Often the question involves looking at a graphic and finding an answer within it, such as the time you need to get on a bus to arrive somewhere else at the right time. The "problem solving in a technology-rich environment" section involved using a laptop computer to demonstrate skills and answer questions, including a fake internet environment. There is a sophisticated design of sampling, question variation and weighting that allows the answers gathered from individuals to be generalised 
to a population. However, this process of data manipulation does not preserve individual results. The actual score obtained by an individual is essentially meaningless; what matters is the pattern obtained when all individual scores are combined.

While the surveys began with a strongly professed interest in literacy per se, over time the latent interest in human capital has become more and more apparent (St. Clair 2013). The OECD website states:

The Survey of Adult Skills (PIAAC) is an international survey conducted in 40 countries that measures the key cognitive and workplace skills needed for individuals to participate in society and for economies to prosper. It measures, in particular: Literacy, Numeracy, Problem solving in technology-rich environments. Educators, policy makers and labour economists will use this information to develop economic, education and social policies that will continue to enhance the skills of adults (OECD in pressa).

Even rapid comparison with the 1997 outcomes cited above shows the extent to which the survey has changed regarding its aspiration to be a policy and economic tool. This is not entirely surprising given the involvement of the OECD, but also reflects a changing domestic policy agenda in Canada and the US.

\section{Methodological approach}

Assessing the impact of an endeavour such as PIAAC on a field such as education is a difficult and deeply political endeavour. The first, and obvious point, is that it is very difficult to comment upon an absence. If there is an observation that, for example, a region has no policy that reflects PIAAC, what does this indicate? Is it a deliberate choice? Has the policy not been developed yet? An additional complexity, discussed below, is that the pan-Canadian adult literacy field, and associated organisations, including in the different jurisdictions within the Federation, have been in some state of crisis for the last few years. Some of the issues around application of, and response to, PIAAC may be a lack of capacity. In this discussion, I do not look in detail at Provincial developments as the task I have set myself is to understand the broad Canadian context.

My own questions in this essay concern the transitions between policy and science and back again. Why is something asked in such a way, and how can the findings be understood in a concrete manner within educational systems? Addressing questions such as these is not a matter of measurement or survey design. Rather, it requires understanding of the various actors involved in the basic skills education system and the context in which they operate. The most appropriate methodology I have encountered for this work is critical policy analysis.

The starting point is, naturally, the understanding of policy. Grimley (1986) states that

in the large, government controlled, bureaucratically organised social apparatus of public education, policy is the expression of the prevailing political 
grouping's ideas of what should be the scope, form and nature of education.

Policies are explicit and implicit statements of value (p. 19).

I would add to this definition that policies hold resource implications (and can be made more or less successful through manipulation of the associated resources) and that in recent years there has been an expectation that the effects of policy should be demonstrable. Policy, then, serves to transform values, will, and intentions into concrete, measurable outcomes within the educational system.

Only over-simplified approaches to policy expect that measurement of policy effects will be straightforward. For example, a policy to provide all new residents of Germany with free program to ensure a working knowledge of the language would seem to be straightforward, and offer many benefits in terms of employability and social engagement. However, when it comes to assessing the effects of the policy things rapidly become extremely complex. What is the cost vs. benefit of such a policy? Politically, what are the unintended consequences? How does the learners' first language literacy change the process? How much German is a "working knowledge"? Does the policy apply to EU citizens or just people new to the Community? As Young (1982, p. 1) argues "the evaluation of policy is a complex task and there is not likely to be any set of readily available criteria upon which particular policies may be judged once and for all."

One response to the lack of clarity is the idea of "evidence-based policy" (Milani 2009) as popularised in the 1990s and 2000s by social democratic governments in the UK, Australia, the USA, and Canada. The general approach is to build evidence for selecting a particular policy choice, taking into account the fundamental impossibility of certainty in evaluation. It is quite reasonable to see the creation of international surveys on learning such as the PIAAC, the Program for International Student Assessment (PISA), and the Trends in International Mathematics and Science Study (TIMSS) as a logical outgrowth of evidence-based policy-making. They represent substantial attempts to generate evidence regarding the effects of educational policies.

It would be possible to accept this framework in its own terms, and view evidence as a irreducibly valuable source of information to assist with planning and delivery of educational services. However, Milani (2009) warns that

it is possible to have bad evidence-based policy-making if the evidence used is biased, flawed or incomplete (...) statistical data as well as cartography are 'texts,' and may be skilfully controlled and technically manipulated (p. 45).

This quote underlines the importance of understanding both the generation and the application of evidence in the policy-making process.

This discussion presents a case of evidence-based policy-making in action or, in this case, inaction. My approach has been to seek evidence that PIAAC has had a demonstrable effect on policy to show how the survey has made a difference. This approach aligns with the New Sociology of Education (eg. Whitty 2002), which emphasizes the importance of looking both at the policy itself and the frame within which it is created. So, in this discussion, I include not only consideration of pan- 
Canadian policy, but also the changing environment in which literacy policies are formed.

Critical policy analysis can be considered to have three stages (Rata 2014). The first is to explore the links between global and local developments. In the current discussion this takes the form of a description of the global development of the adult surveys led by the Organisation for Economic Cooperation and Development (OECD) and consideration of basic education for adults in Canada. The second stage is exploring policy within that context, which involves looking at the ways in which Canadian discourse around adult skills reflects the PIAAC framing and meaning-making. The third stage is empirical exemplification of the analysis through discussion of the ways PIAAC derived concepts and language have effected the basic education field in Canada.

The data I have used to inform my argument takes the form of reports from various governmental levels, including the OECD, media surveys, writings of those involved in the political process at the Federal level, and curriculum and assessment documents. I also draw upon my own knowledge of the field where necessary. Unfortunately this is more often necessary than I would like as the current capacity for scholarship in adult literacy in Canada is limited. On occasion, I dip into provincial information in order to illustrate a point or a particular development. My interest is not the quantification of literacy in general, about which others have written (cf. Quigley et al. 2006), but specifically the ways in which the PIAAC survey has had an impact upon policies in Canada.

In this article, I will not be discussing technical issues of the surveys, which I have covered elsewhere (St. Clair 2013). These aspects of the surveys, while important, have little relevance to the use of the data and ideas of PIAAC within the policy environment. Usually people acknowledge the methodological shortcomings of data generation and analysis and then continue to work with the findings on the assumption that they must indicate something even if they are not as accurate as they could be. This is worrying but perhaps not surprising given the wider policy environment.

This paper presents a critique of the application of evidence that was designed specifically for policy utility and yet has not achieved that use. Based on documentary data I show that it is difficult to provide clear evidence supporting claims that PIAAC outcomes have enriched, or even had an impact upon, the policy context. While some may have reservations about the generation of the evidence, the specific concern here is its utilisation.

\section{The context for basic education in Canada}

It is interesting to review the different terms used to refer to education for adults in Canada. The oldest term for adults learning to read, write, and compute is "adult literacy." The term "literacy" applied only to adults quite consistently until the mid1990s, making it possible to identify somebody as a "literacy tutor" with confidence that it would be understood that they worked with adult learners. Adult literacy often included the political project of empowering marginalised people. This wasn't 
true in all cases, but certainly a non-functionalist, Freire-inspired approach was discernible. The term "literacy" was eventually adopted across multiple sectors and lost the clear reference to adult learning.

"Adult Basic Education" followed, with an initial emphasis on more employment and instrumentally focused education. Over time, many jurisdictions used adult basic education to refer to study leading to Grade 12 (high school graduation) equivalency. Unlike many jurisdictions around the world, Canada shares with the United States a somewhat generic diploma for the end of High School. Entry to further study is determined by the courses taken in high school while obtaining the diploma, but for many employment opportunities possession of the certificate itself is evidence of qualification. In this context "basic" refers to the level of education needed for employment and leads to the "post-secondary" education needed for professional or specialist roles. The vocational flavour of the term adult basic education may derive from this implied positioning.

"Basic skills" can also be found in Canada, arising from the extent to which communicative competencies can be seen as foundational for later learning and professional employment. More recently the term "essential skills" has been adopted, particularly at Federal level and in Ontario. This term tends to capture a far wider range of elements than the older ideas, and is intended to capture the entire portfolio of abilities needed for a specific role. In Ontario one can visit a webpage that indicates the levels of essential skills needed for specific jobs (e. g. en.esot.essentialskillsgroup.com/?p=occup).

The language of adult competencies, as used in PIAAC, has not been widely adopted in Canada to this point, though the essential skills approach is quite similar. While the notion of competencies is troubled in the UK (Coffield 2000) this is not the case in Canada and the US, where there may be more comfort with instrumental ends for adult education. It certainly seems possible that the concept of competencies is going to become more influential in practices and the language that describes them.

In this discussion, I will use the term "adult literacy education" (ALE) as it represents the clearest definition and does not close down the political project as powerfully as other terms. It is important to understand the other ways in which this domain can be addressed as the language is so inconsistent, but my aim is to present a relatively coherent analysis of developments whatever they are called.

The Canadian federal system of ten provinces and three territories adds considerable complexity to the situation for any educational policy. The Constitution allocates power over education to the provinces and territories, while workforce development remains with the Federal government. ALE sits, in some views, exactly on this division, with one foot in education and the other in the area of workforce and employment. The list of terms reviewed above often reflect this divide, and can be read as attempts either to reflect the role of ALE or to push it in a certain direction for political ends. Given the lack of clarity regarding who actually has responsibility for ALE - and the need to fund it - a compromise has developed over time. The Federal government has supported research and strategizing in ALE while the other jurisdictions have funded and supported delivery. Not unnaturally, this has led to situations where money that is technically dedicated to research and strategy is used for "pilot" delivery programs, often for a number of years. 
One remarkable Canadian initiative was the National Literacy Secretariat, located within the Federal government. Initially this was a small literacy support unit within the Secretary of State's office, but it moved in time to the ministry responsible for human resources and social development. The philosophy of the unit was strongly community-based despite its location within the Federal government, and it supported a great many initiatives across the country. Some of these went on to be funded by provinces or other levels of government and became part of the semi-permanent literacy infrastructure. In more recent years the unit has become the Office of Literacy and Essential Skills, to all intents and purposes a workforce development agency (Hayes 2015a).

Until recently there were five national bodies (more strictly speaking "pan-Canadian") that received Federal support for cross-Canadian coordination. They included a Francophone organisation, a database of literacy resources, an Indigenous organisation, one that was more directly involved in the corporate sector, and one focused strongly on research. The former Federal government withdrew support from the field, resulting in the closure of all but one of these organisations. In addition, the majority of provincial organisations lost support and closed their doors (Hayes 2015a). The loss of these bodies was an enormous setback for the field.

The majority of organisations primarily involved in Canadian adult literacy are non-profit agencies closely focused on delivery that fits their local contexts. The type of program that works well for a large, high-immigration city such as Vancouver will not work for a small rural community in Manitoba, so the variation is striking. Every element, from availability of volunteers to perceived needs, will be quite different. This localisation of effort and focus has advantages for the field and for learners. However, there are also challenges concerning collective action and ways to build the field on a broader level.

The disappearance of cross-cutting agencies reduces still further the opportunities for collective development, already challenged by the 13 jurisdictions. The support of the Federal government made it possible for the field to have a relatively coherent voice on issues across jurisdictions and, perhaps equally importantly, within jurisdictions. If a provincial organisation wished to challenge the provincial government, federal funding provided a measure of protection for that organisation. While there are still some province-wide organisations, they are primarily funded by the province and less able to act without at least some concern for repercussions.

In addition to non-profit agencies, providers of adult literacy include school districts and community colleges. The schools in many provinces offer free upgrading to grade 12, though it is often delivered in a school-like setting. Colleges offer adult literacy as foundational skills or study preparation. While this has often been without charge (unlike many other college courses) there has been a recent move in British Columbia to permit colleges to charge tuition for these programs.

Overall, ALE in Canada is delivered through the three sectors of non-profit agencies, school districts and colleges, with slightly different emphases in each case. In surveying the current situation the strongest impression I have is deep fragmentation. The unity of the field is challenged by the split jurisdiction between education and workforce development, and the bodies able to bridge this chasm have very significantly eroded. In this context, it is inevitable that the uptake of both the framework 
offered by PIAAC and its findings has been patchy and inconsistent. In some cases the notion of five levels of competence has seen widespread support and application, with assessment and curricular materials constructed around these ideas. In other cases PIAAC has had little or no discernible effect upon practices and policy. This situation would not be surprising but for the considerable and long term investments Canada has put into the international adult survey series.

\section{The history of PIAAC in Canada}

The Canadian government has been involved heavily in national and international surveys of adult abilities since the early 1990s. There is a chain of studies from the IALS 1994, through the ALLS of 2003 to the PIAAC. All share very similar methodology and a similar theoretical view of literacy. The first of these studies had 17 countries participating, the second had seven, and PIAAC was the furthest reaching with a final tally of 40 . Canadian agencies and social scientists have been involved since the beginning of the series.

The definition of literacy used throughout the series is the UNESCO definition: "using printed and written information to function in society, to achieve one's goals, and to develop one's knowledge and potential" (Kirsch and Murray 1997, p. 17). The leaders of the initiative add:

The first objective was to develop scales that would permit comparisons of the literacy performance of adult with a wide range of abilities. Then, if such an assessment could be created, the second goal was to describe and compare the demonstrated literacy skills of adults in different countries. This second objective presented the challenge of comparing literacy across cultures and across languages (Kirsch and Murray 1997, p. 16).

This sequence of surveys has used the same working model of literacy skills throughout its various iterations. The "correct" answers demonstrate "salience" defined as "the ability to find and extract sufficient information form among highly relevant information in the stimulus material" (Kirsch and Guthrie 1980, p. 91). The authors add four further variables that make this task harder: the order in which information is presented, the amount of information, whether the exact words and typography of the question matched the required response, and the total number of information categories that need to be considered. While this is quite a sophisticated measurement model it is also narrow in the way it conceives of literacy. Writing is not considered, only the ability to find answers to questions in a given text. This is not strongly consistent with more recent models regarding the use of written language (Hamilton and Barton 2000) but remains the central concept of the PIAAC literacy survey.

Canada's deep involvement in the international adult survey series can be considered as something of a historical accident. The main agency driving the Canadian role was Statistics Canada (StatsCan) a Federal agency that conducts the census and other wide-ranging data collection efforts. In the early 1990s StatsCan became involved in the International Adult Literacy Survey, which at the time was an inno- 
vative relatively small-scale survey of adult skills, and contributed a great deal of expertise to the development of instruments and the data collection process. The Director of the Special Surveys Division at StatsCan, Scott Murray, was especially active in the development and promotion of the IALS. Murray was International Study Director for the IALS and its next iteration, the ALL.

To some extent the drift towards a more economic view of the value of the surveys has reflected, or at least paralleled, the politics of Canada. In the 1990s the National Literacy Secretariat supported a progressive view of literacy and numeracy as drivers of personal and social development. When they moved from the Secretary of State's office into the ministry responsible for workforce development (the name of this ministry has changed several times - it is currently Employment and Social Development) the expectations for the Secretariat began to change. The transformation into the Office of Literacy and Essential Skills finalised and underlined this transformation. These changes occurred as a more progressive Liberal government was replaced by a centre-Right Conservative administration. Over the same period a more directly productivity-centred discourse started to appear in education, in education for adults, and in the type of data useful for governance.

Canada has maintained its commitment to the surveys while other countries have come and gone. This is well demonstrated in PIAAC, where the Canadian sample size was 27,285 , representing a very significant financial investment, and by far the biggest sample in the survey. The hope was that this sample size would permit rigorous analysis of sub-populations such as First Nations and more local areas.

If we were to expect any country to demonstrate the value of large scale adult surveys it would be Canada. The government(s) have supported this series of surveys since their inception, have found them moving in parallel with their own concerns, and have continued to invest very significantly in the collection and analysis of data. In the next two sections I turn to the situation in practice in order to trace the direct effects of PIAAC on Canadian adult literacy education.

\section{PIAAC in policy}

One of the most striking aspects of PIAAC in Canadian policy, especially given the effort and resources put into the development of the surveys, is the relative absence of PIAAC data and framing in the adult literacy scene. Both at provincial and federal level, there are few substantive traces of the work that has been done. It would be reasonable to expect that PIAAC would permeate the field in Canada this is absolutely not the case. The reasons for this are hard to discern, but may point towards a fundamental weakness of the PIAAC survey. The data collection and analysis methods do not appear to capture changes over time.

In Canada's case, there are three sets of data available. In the first survey, the IALS, 42.2 percent of Canadians were estimated to be in the least skilled two levels of prose literacy (OECD 2000) (IALS distinguished between two types of literacy, this distinction was abandoned in PIAAC). The Canadian report on the PIAAC cautions very strongly against comparing the ALL results of 2003 with the PIAAC of 2012, and then does so. When adjusted for comparability, the ALL suggests 
that 37 percent of Canadians were at level 1 or 2 in literacy, and 5 percent were below level 1. This last category was an innovation in the ALL, in an attempt to avoid simply clumping non-respondents together irrespective of their reasons for not responding. It should not be assumed that these individuals were incapable of responding to the survey, though this how it is often interpreted. These were qualified individuals who did not successfully complete the screening portion of the survey, but there is no information on why they did not. Finally, in the PIAAC, the estimate is 45 percent at level 1 and 2 with 4 percent below level 1 (Statistics Canada \& Employment and Social Development Canada 2013).

These figures illustrate a very significant issue with the surveys. While they appear to be a longitudinal time series, they actually are not. The methodology is fundamentally similar, but the weighting and other procedures have evolved over time. Based on the published results, 42 percent Canadians aged from 16 to 65 had low skills in 1994 and six years later it had dropped to 37 percent of the population. This is around a million people who had been estimated to have different levels of skills by these two surveys. This could have been interpreted as good news by policymakers and by the adult literacy field, though there was mainly silence. Just as well, as 12 years later, the proportion of the population estimated to have low skills was at an all-time high of 45 percent - meaning that over a million people had lost the skills they were previously estimated to possess. This could have been interpreted as bad news by policymakers and the adult literacy field, so the silence was perhaps less surprising.

The point here is not to criticise the survey developers for improving their methodology, but to underline that these figures are quite unhelpful for the design of policy. If we accept the notion that politicians wish to see results within their term, measures that are over a decade apart do not help. Added to this that the field cannot point to a clear trend over time and the results appear to add much more confusion than they resolve. For politicians it would make much more sense to have a simple, cheap, frequent measure (Wagner 2005).

It also remains unknown how sensitive the PIAAC results are; that is, how many people need to learn how much in order to show up in the results. For policy, this can be translated to costs. How much would need to be invested to bring the percentage at level 1 and 2 down by 5 percent? It seems obvious that the cheapest route would be to tackle individuals at the high end of level 2 and move them to 3 , but nobody knows what this actually means, especially since the measures are aggregate and only refer to individuals in a relatively abstract way.

The percentage at levels 1 and 2 is important because the OECD initially declared that level 3 was the minimum needed to function in an industrialised society. People with level 1 and 2 skills were therefore deemed to have a problem, irrespective of whether people were happy with their skill level ( $90 \%$ of all respondents were). Eventually OECD changed their view of level 3 and withdrew the reference from their documentation (author) but many still view level 3 as the functional literacy "watershed."

The PIAAC results do offer some guidance for policy, though at the time of writing it is not clear how this information will actually be used. Because of the massive Canadian sample size it is possible to compare sub-populations with a reasonable 
level of confidence, with three results especially pertinent. Indigenous people consistently obtain lower scores than non-Indigenous people, with this difference especially marked for those living in the three Northern Territories of Canada. Immigrants to Canada tend to demonstrate lower scores than people who were born in the country. Finally, analysis of official language minorities shows that Francophones consistently score lower than Anglophones, even in Québec (a province that is officially Francophone) (Statistics Canada \& Employment and Social Development Canada 2013).

The first two findings provide support for policy directed at these populations. In the case of Indigenous people, the education gap is widely recognised and has been a priority for the Liberal government (elected in October 2015). Similarly, support for New Canadians is a historical commitment of both provincial and federal governments. The challenge is translating these findings into adult literacy education strategies - such efforts have been significantly undermined by the argument that return on investment is far higher for a child than an adult (cf. Heckman 2008). The third finding is more troubling, and suggests that there may be inconsistencies in the instruments used for different linguistic groups.

There is little evidence that the PIAAC framing of literacy, numeracy and problem solving in technology rich environments has been influential in policy, or that the findings have made a difference. There are occasions when the "headlines" of the survey are used in an alarmist way to express concerns about the state of the human capital in Canada, such as "Adding up the ways we're falling behind in education" (Wells 2013). The programs implemented in response to these alarms were almost entirely focused on job training and not basic education. The most significant program, the Canada Jobs Grant, was estimated to have reached 10 unemployed people out of 11,707 trainees. This involved 2200 grants to employers, none of which had anything to do with adult literacy (Hayes 2015b).

It seems that there are legitimate questions to be raised about the utility for, and impact upon, Canadian policy arising from the surveys. In this realm it appears that the differences between the pre- and post-PIAAC policy reality are currently quite limited.

\section{PIAAC flavoured delivery}

The impact of PIAAC on policy does not appear to be very strong; it is even less notable in the realm of practice. On one level this makes sense. A population level estimate is not designed to inform or measure individual learning, and there are a number of cautions about assuming that the results can be applied at the individual level (St. Clair 2013). The entire frame of the adult literacy survey series is to use data gathered from individuals to estimate population characteristics, so the measures do not make sense at the level of a single person. However, the five level framework may be useful for individual learners as a way to assess skills and measure progress. Making this feasible is a totally separate exercise from the population skills measurements, as it requires taking the scales from PIAAC (from 0 to 500) and creating instruments that can map an individual's test results directly on 
to them. It is important to emphasise once more that this is different from population surveys, where information from individuals is pooled before estimations are made.

The OECD have worked with the European Union to create a tool for individual assessment called the "E\&S Online" (OECD in pressb). It is described as being linked to the PIAAC results so that individuals can benchmark themselves against the international measures and even as a potential diagnostic tool to identify skills gaps and areas that individuals need to strengthen. People who have worked in adult literacy education would generally view these claims as relatively ambitious. It is extremely challenging to design assessment tools that provide both the generalisation power to extend to a population measure and the detail to identify learning goals. At the time of writing (May 2016) there are several demo tests available, but the Canadian English and French tests are not among them even though they are listed as being developed.

The area of Canada that has gone the furthest in bringing PIAAC into a practice setting is the Province of Alberta. The framework for adult literacy is "Living literacy: A literacy framework for Alberta's next generation economy" (Alberta 2009). The document uses the PIAAC indicators as the heart of its methodology, and states the intention that "By 2020, 70 percent of Albertans will have a minimum of level 3 on international adult literacy measures" (p. 9). They note that the measurement of this goal will require the development and deployment of a standardised assessment. The development of the Alberta policy took place before the PIAAC, and there appears to have been little updating. It is worth noting that the PIAAC results show that by 201255 percent of Albertans were at level 3 or above. It is also not as challenging a goal as it appears because of the demographic trends - younger cohorts tend to score more highly due to improvements in education and higher demands for schooling, so an upward trend is evident even without intervention.

The documents list a range of targets for adult literacy education as well as actions to be taken in support of these outcomes. These include action plans, more accessible programming, partnership facilitation, building awareness, program and service coordination, and standardised tools and curriculum (Alberta 2009). It is not clear to what extent the adult literacy survey conceptions permeate this provision, and to what extent it implies an outcome measure.

Seven years after the adoption of this ambitious framework, which set out to transform the field in the Province, there is little evidence that it has affected practice. The one area that has received considerable attention and support is the Alberta Reading Benchmarks, as developed by Bow Valley College in Calgary (Erdman 2014). These benchmarks, designed to work with learners with lower tested skills, explicitly articulate to the measures used in the IALS and ALL, but not so well to the PIAAC measures. The author of the benchmarks is careful to specify that they should not be used for curricular selection and development nor for program evaluation. They are intended simply to allow practitioners to judge learner progress. So while they may make a difference to the measurement of learning, they do not require or recognise any particular changes in the teaching and learning process.

During the period in which the adult literacy surveys have been implemented, Canadian jurisdictions have continued to develop and implement curriculum and assessment tools. In Ontario, Canada's most populous province, there is an Adult 
Literacy Curriculum Framework (Community Literacy 2013) which features a strong emphasis on work preparation and readiness for further study. There is little reference to other uses for adult literacy education. Some of the recommended assessment tools refer back to IALS, though the surveys are not directly influential on the curriculum. In British Columbia management of community literacy services is outsourced to a not-for-profit agency called Decoda. This agency has developed and implemented a set of detailed and theoretically grounded Community Adult Literacy Benchmarks (Decoda 2016). There is no reference to PIAAC or the other adult literacy surveys.

In reviewing the Canadian adult literacy education context, it seems that practices have not been substantially influenced by the adult literacy surveys. It is challenging to find definitive evidence that the post-PIAAC practice world is really very different from what it would have been without the surveys. The hope that having the data and framework from the surveys would transform the field is some way from realisation, and it may be that having the OECD more involved in the survey makes this less likely. The PIAAC pointed the way to a more explicitly human capital-oriented frame for the survey series, and this moves it further away from the possibility of making easy connections between the survey results and practices.

\section{Possible futures}

This review suggests that the post-PIAAC world of adult literacy education in Canada is not very different from the pre-PIAAC world. There continue to be 13 jurisdictions shaping their own approach to the field, with few shared tools or methods. One reason for this apparent lack of influence, I have suggested, is the changes between the iterations of the survey, which significantly undermines the ability to make time series comparisons with the data. A second reason is the loss of interest in, and dismantling of, the national and provincial literacy infrastructure, which unfortunately came at the same time as the PIAAC data began to flow.

There is to be ongoing research on the PIAAC dataset in the USA and, to a more limited extent, in Canada. A lot of this work delves deeper into the background information the survey collects, such as involvement in adult education programs. With a sample of 27,000 this is a very significant dataset and deserves to be examined in depth. Unfortunately, there is often a lack of detail in the information which prevents truly insightful analysis.

Canada has invested very significantly in the production of the adult literacy survey series, and it would be unfortunate if it did not demonstrate positive outcomes in its influence on the field. While there are shortcomings in the surveys (as there always are) there is a great deal of potential for wise and beneficial development of the instrument and its findings. There can be little doubt that the primary requirement for the potential to be realised is resources. These would be applied to the development of materials and curriculum, and the completion of the E\&S Online survey discussed above. The second requirement would be pan-Canadian management cutting across the 13 jurisdictions. While none has the ability to con- 
tinue development alone, together there is a possibility that some interesting and influential applications of the survey might be developed.

I would suggest that one key to taking the surveys forward would be the refinement of the theoretical model of literacy at the heart of the methodology. The survey would need to be reclaimed by the field internationally, and brought to bear more directly upon the basic skills teaching and learning sector. With the PISA survey there has been great interest in the working conditions and teaching approach in the nations that score well. There is certainly the same type of question to be asked about adult literacy education and adult competencies. At this point one of the fundamental questions that remains unclear is "what motivates people to upgrade their skills and how can this be made easier for them?" This would, I believe, be an essential question for the next iteration, and have real resonance for the field. The generalisation of the adult literacy surveys to an ill-defined proxy for human capital allows more general statements to be made about economies, but it undermines their utility as educational tools, and is, finally, quite circular. In this model, the level and type of skills required are those that generate the highest GDP, but there is evidence that having a high GDP goes a long way to supporting the skills development of the population (Hanushek and Woessmann 2008).

In many ways, Canada is at a crossroads with the adult literacy surveys. The choice to be made is whether to continue the surveys and invest in the development and implementation of tools based on the findings and the framework, or to withdraw entirely. It does not seem sustainable to continue to invest significant money and time in the surveys but not have a means to follow through on the information so expensively produced. Which path to follow is a decision primarily for policymakers, though it is to be hoped that the field can have some input. The decision made will lead to one of two post-PIAAC worlds, which will be very different environments for the future of adult literacy education.

Open Access This article is distributed under the terms of the Creative Commons Attribution 4.0 International License (http://creativecommons.org/licenses/by/4.0/), which permits unrestricted use, distribution, and reproduction in any medium, provided you give appropriate credit to the original author(s) and the source, provide a link to the Creative Commons license, and indicate if changes were made.

\section{References}

Alberta Advanced Education and Technology (2009). Living literacy: a literacy framework for Alberta's next generation economy. http://eae.alberta.ca/media/219400/living\%20literacy.pdf. Accessed 11 Feb 2016.

Coffield, F. (2000). The necessity of informal learning. Bristol: The Policy Press.

Community Literacy of Ontario (2013). Ontario adult literacy curriculum framework. http://literacybasics. ca/assessment/ontario-adult-literacy-curriculum-framework/. Accessed 7 Mar 2016.

Decoda (2016). Community adult literacy benchmarks. http://www.decoda.ca/practitioners/adult-literacypractitioners/community-literacy-benchmarks/. Accessed 11 Feb 2016.

Erdman, C. R. (2014). Alberta reading benchmarks for adults. Calgary: Bow Valley College.

Grimley, J. (1986). Critical educational policy analysis: a discussion of perspectives. Australian Journal of Teacher Education, 11(2), 19-26.

Hamilton, M., \& Barton, D. (2000). The International Adult Literacy Survey (IALS): what does it really measure? International Review of Education, 46(5), 377-389.

Hanushek, E., \& Woessmann, L. (2008). The role of cognitive skills in economic development. Journal of Economic Literature, 46(3), 607-688. 
Hayes, B. (2015a). The state of adult literacy in Canada - an overview. https://brigidhayes.wordpress.com/ 2015/08/28/the-state-of-adult-literacy-in-canada-an-overview/. Accessed 6 Mar 2016.

Hayes, B. (2015b). Canada Jobs Grant an "amazing success:" but for whom? https://brigidhayes. wordpress.com/2015/05/11/canada-job-grant-an-amazing-success-but-for-whom/

Heckman, J. J. (2008). Skill formation and the economics of investing in disadvantaged children. Science, 312(5782), 1900-1902.

Kirsch, I.S., \& Guthrie, J. T. (1980). Construct validity of functional reading tests. Journal of Educational Measurement, 17(2), 81-93.

Kirsch, I. S., \& Murray, T. S. (1997). Introduction. In T. S. Murray, I. S. Kirsch \& L. Jenkins (Eds.), Adult literacy in OECD countries: technical report on the first international adult literacy survey NCES no. 98053. Washington: National Center for Educational Statistics.

Milani, C. R.S. (2009). Evidence-based policy research: critical review of some international programmes on relationships between social science research and policy-making. Paris: UNESCO.

Organisation for Economic Cooperation and Development (in press a). Skills. Available at: http://www. oecd.org/skills/

Organisation for Economic Cooperation and Development (in press b). Education and skills online assessment. Available at: http://www.oecd.org/site/piaac/ENG_Brochure\%20Education\%20and\%20Skills $\%$ 20Online_Nov14.pdf

Organisation for Economic Cooperation and Development (2000). Literacy in the information age: final report of the International Adult Literacy Survey. Paris: OECD.

Organisation for Economic Cooperation and Development (2016). About PIAAC. http://www.oecd.org/ skills/piaac/surveyofadultskills.htm. Accessed 22 Jan 2016.

Quigley, B. A., Folinsbee, S., \& Kraglund-Gauthier, W.L. (2006). State of the field report: adult literacy. http://aamt-awpl.ca/wp-content/uploads/Adultliteracy.pdf. Accessed 22 Jan 2016.

Rata, E. (2014). The three stages of critical policy methodology: an example from curriculum analysis. Policy Futures in Education, 12(3), 347-358.

St. Clair, R. (2013). The limits of levels: understanding the international adult literacy surveys. International Review of Education, 58(6), 759-776.

Statistics Canada \& Employment and Social Development Canada (2013). Skills in Canada: first results from the Programme for the International Assessment of Adult Competencies (PIAAC). Ottawa: Statistics Canada.

Wagner, D. (2005). Monitoring and measuring literacy. Paper commissioned for the EFA global monitoring report 2006, literacy for life. Paris: UNESCO.

Wells, P. (2013). Adding up the ways we're falling behind in education. Maclean's. http://www.macleans. ca/authors/paul-wells/adding-up-the-ways-were-falling-behind/. Accessed 22 Jan 2016.

Whitty, G. (2002). Making sense of educational policy. London: SAGE.

Young, R. (1982). Progressive and degenerating policy theories. In R. Young, M. Pusey \& R. Bates (Eds.), Australian educational policy issues and critique. Deakin: Deakin University Press. 